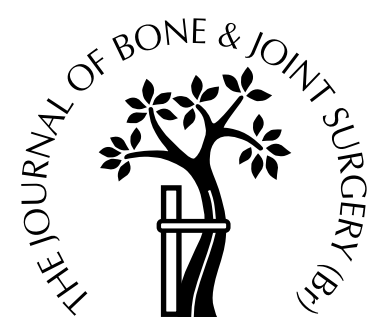

\title{
Long-term results of retention of the posterior cruciate ligament in total knee replacement in rheumatoid arthritis
}

\author{
Gurdev S. Gill, Atul B. Joshi
}

From Lubbock, Texas, USA

W e analysed the long-term results with a mean follow-up of 10.2 years, of 66 total knee replacements in 42 patients with rheumatoid arthritis. In all cases the posterior cruciate ligament was retained.

There were only three complications (4.5\%).

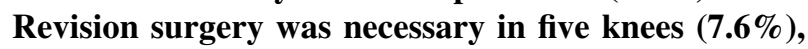
including one $(1.5 \%)$ with infection. At the final follow-up, $\mathbf{7 5 . 8 \%}$ of knees were rated excellent clinically. Only $15 \%$ had an excellent function score. The survival rate of the implant was $90.7 \%$ at 19 years.

The clinical, radiological and survivorship analysis shows that the posterior-cruciate-retaining knee arthroplasty performs well in rheumatoid arthritis.

J Bone Joint Surg [Br] 2001;83-B:510-2.

Received 20 May 2000; Accepted after revision 12 September 2000

Total knee replacement (TKR) is the mainstay of treatment of knees affected with rheumatoid arthritis. An unresolved controversy is whether to retain or excise the posterior cruciate ligament (PCL). ${ }_{5,6}^{1-4}$ Few studies have a follow-up of longer than ten years. 5,6

We present the long-term results of a prospective study of retention of the PCL in TKR in patients with rheumatoid arthritis.

\section{Patients and Methods}

Between 1976 and 1987, one surgeon (GSG) carried out 66 primary TKRs in 42 patients with rheumatoid arthritis, retaining the PCL in all cases. The mean age of the 10 men and 32 women at the time of surgery was $61.3 \pm 10.4$ years (30 to 77). January 2000 was designated the final follow-up date. At that time, 25 patients (38 knees) had died leaving

G. S. Gill, MD

A. B. Joshi, MD, MCh Orth, FRCS

3601, 22nd Place, Lubbock, Texas 79201, USA.

Correspondence should be sent to Mr A. B. Joshi.

(C)2001 British Editorial Society of Bone and Joint Surgery 0301-620X/01/411398\$2.00
17 (28 knees) available for review. No patient was lost to follow-up. All patients were reviewed within one year of their last follow-up. The mean follow-up of all patients was $10.3 \pm 5.4$ years $(0.2$ to 19.8$)$ and that of living patients $14.9 \pm 1.8$ years (12.9 to 19.8$)$.

There were 31 right and 35 left knees. Three (4.5\%) had undergone previous surgical procedures. In 43 knees $(65.1 \%)$ there was a fixed flexion contracture with a mean value of $18.5 \pm 4.8^{\circ}$ (5 to 30 ). There were valgus deformities in 38 knees (57.6\%). The remaining 28 (42.4\%) were in neutral. No knee had a varus deformity.

We used the Total Condylar Prosthesis (Howmedica, Newark, New Jersey) from 1976 to 1982 and the Kinematic Condylar Prosthesis (Howmedica) from 1982 onwards. The overall results of the Kinematic Condylar Knee arthroplasties have recently been published. ${ }^{7}$ The purpose of this paper is only to consider problems related to rheumatoid arthritis. The operative technique has been described previously. ${ }^{1-8}$ The patellae were resurfaced in all knees. All procedures were done without body-exhaust suits or laminar airflow, but antibiotics were routinely administered.

Limb alignment was assessed before and after operation. Clinical evaluation was undertaken at two and six weeks, six months, one year, and at variable intervals after that until the final follow-up. Clinical evaluation was based on the scoring system of the Knee Society, ${ }^{9,10}$ with a score of 85 or more being considered excellent and of less than 60 , poor.

Statistical analysis. We used Kaplan-Meier analysis to calculate survivorship and actuarial methods to draw up a life table. ${ }^{11}$ The first endpoint for survival was removal or revision of any component for any reason, and the second, or 'worst scenario', endpoint was revision and moderate pain (a pain score of less than 45) at final follow-up. We used the Wilcoxon signed-rank test to compare such variables as preoperative and postoperative clinical scores and range of movement. In all analyses, $\mathrm{p}$ values of less than 0.05 were considered to be significant. We used analytical software (StatsDirect, Camcode, Herefordshire, UK).

Results

The mean preoperative knee score of $33.6 \pm 14.7$ points improved significantly to $85.0 \pm 29.5$ at the final follow-up 
Table I. Actuarial life table for all 66 knees, with an endpoint of revision of a component for any reason

\begin{tabular}{|c|c|c|c|c|c|c|c|c|}
\hline $\begin{array}{l}\text { Interval } \\
(\mathrm{yr})\end{array}$ & $\begin{array}{l}\text { Number at start } \\
\text { (at risk) }\end{array}$ & Revised & Intact knees & Lost to follow-up & Withdrawn & $\begin{array}{l}\text { Adjusted number } \\
\text { of knees at risk }\end{array}$ & $\begin{array}{l}\text { Survival rate } \\
(\%)\end{array}$ & $\begin{array}{l}\text { 95\% Confidence } \\
\text { intervals }\end{array}$ \\
\hline 0 to 1 & 66 & 0 & 66 & 0 & 3 & 64.5 & 100.0 & - \\
\hline 1 to 2 & 63 & 1 & 62 & 0 & 6 & 60 & 100.0 & - \\
\hline 2 to 3 & 56 & 1 & 55 & 0 & 2 & 55 & 98.3 & 88.7 to 99.8 \\
\hline 3 to 4 & 53 & 0 & 53 & 0 & 1 & 52.5 & 96.5 & 86.9 to 99.0 \\
\hline 4 to 5 & 52 & 2 & 50 & 0 & 2 & 51 & 96.5 & 86.9 to 99.0 \\
\hline 5 to 6 & 48 & 0 & 48 & 0 & 2 & 47 & 92.7 & 81.8 to 97.2 \\
\hline 6 to 7 & 46 & 1 & 45 & 0 & 3 & 44.5 & 92.7 & 81.8 to 97.2 \\
\hline 7 to 8 & 42 & 0 & 42 & 0 & 4 & 40 & 90.7 & 78.9 to 96.0 \\
\hline 8 to 9 & 38 & 0 & 38 & 0 & 2 & 37 & 90.7 & 78.9 to 96.0 \\
\hline 9 to 10 & 36 & 0 & 36 & 0 & 2 & 35 & 90.7 & 78.9 to 96.0 \\
\hline 10 to 11 & 34 & 0 & 34 & 0 & 4 & 32 & 90.7 & 78.9 to 96.0 \\
\hline 11 to 12 & 30 & 0 & 30 & 0 & 3 & 28.5 & 90.7 & 78.9 to 96.0 \\
\hline 12 to 13 & 27 & 0 & 27 & 0 & 12 & 21 & 90.7 & 78.9 to 96.0 \\
\hline 13 to 14 & 15 & 0 & 15 & 0 & 4 & 13 & 90.7 & 78.9 to 96.0 \\
\hline 14 to 15 & 11 & 0 & 11 & 0 & 3 & 9.5 & 90.7 & 78.9 to 96.0 \\
\hline 15 to 16 & 8 & 0 & 8 & 0 & 3 & 6.5 & 90.7 & 78.9 to 96.0 \\
\hline 16 to 17 & 5 & 0 & 5 & 0 & 1 & 4.5 & 90.7 & 78.9 to 96.0 \\
\hline 17 to 18 & 4 & 0 & 4 & 0 & 2 & 3 & 90.7 & 78.9 to 96.0 \\
\hline 18 to 19 & 2 & 0 & 2 & 0 & 1 & 1.5 & 90.7 & 78.9 to 96.0 \\
\hline 19 up & 1 & 0 & 1 & 0 & 1 & - & 90.7 & 78.9 to 96.0 \\
\hline
\end{tabular}

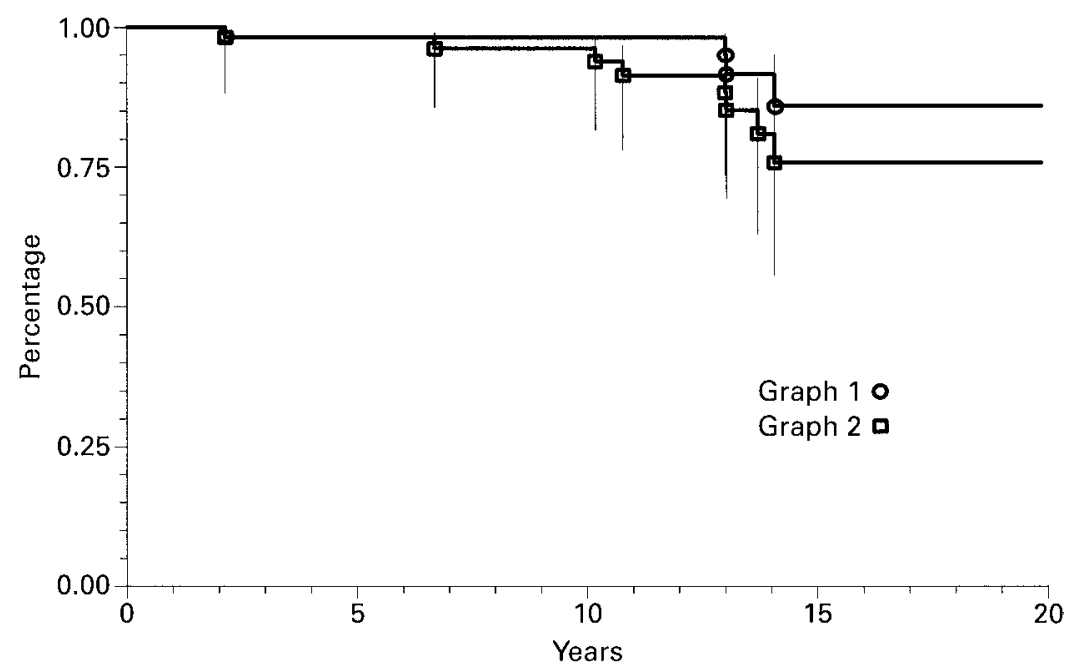

Fig. 1

Graphs showing the survival rates of the implants for the 42 patients (66 knees) who had TKR with PCL retention. Graph $1(\mathrm{O})$, survival endpoint is revision of a component for any reason; graph 2 (コ), 'worst scenario' survival endpoint is revision and moderate pain. $(\mathrm{p}<0.0001)$. The clinical results were excellent in 50 knees $(75.8 \%)$ and poor in eight $(12.1 \%)$. The mean preoperative function score of $36.5 \pm 19.1$ points improved to $39.6 \pm$ 34.4 , which was not significant $(\mathrm{p}=0.574)$. At the final follow-up, function scores were excellent in only $15 \%$ of knees.

There was a significant difference in flexion, $106.36 \pm$ $37.0^{\circ}$ at follow-up compared with $88.7 \pm 29.3^{\circ}$ before operation $(p<0.0001)$. About $79 \%$ of knees had $100^{\circ}$ of flexion or more. There was collateral instability of $5^{\circ}$ to $10^{\circ}$ in $6 \%$ of knees; the remaining $94 \%$ were stable. Fixed flexion contracture was present in seven knees (10.6\%) and averaged $6.5 \pm 3.2^{\circ}$ at follow-up. Overall, knee alignment was a mean of $5.9^{\circ}$ of valgus (0 to 10$)$. At the final followup there was less than $2 \mathrm{~mm}$ of cement-bone lucency in five femoral (7.6\%), 12 tibial (18.2\%) and six (9.1\%) patellar components. Lucency of more than $2 \mathrm{~mm}$ was not observed.

There were three complications (4.5\%); two patients had wound dehiscence and one a delayed supracondylar fracture. At the final follow-up, five knees $(7.6 \%)$ had failed. Of these, one $(1.5 \%)$ had been revised for infection, three (4.5\%) for aseptic loosening and one for instability.

Table I is a life table for all 66 knees. Figure 1 shows the survival of the implant. Taking removal or revision of a component for any reason as the endpoint (graph 1), there 
was an survival rate of $90.7 \%$ from 8 to 19 years (confidence interval (CI), 79 to 96). Using the 'worst scenario' as the endpoint (graph 2), the implant survival rate was $85.2 \%$ (CI 72.3 to 92.4 ) at ten years and $75.8 \%$ (CI 56.4 to $87.3)$ at 19 years.

\section{Discussion}

About $1 \%$ of the population has rheumatoid arthritis, ${ }^{12}$ a progressively disabling disease which usually affects many joints. Up to $93 \%$ of patients with long-standing rheumatoid arthritis have at least one, and often both, knees affected. $^{12}$ TKR, which aims to relieve pain and improve function, has become the principal procedure in the treatment of knees destroyed by rheumatoid arthritis. Most reports quote rates of survival of the implant of $90 \%$ to $97 \%^{3,13-17}$ with a follow-up of less than ten years. Few studies have longer follow-up. 5,6

There is debate about whether to retain or excise the PCL. ${ }^{18-20}$ Laskin and O'Flynn ${ }^{3}$ reported a higher rate of failure with PCL retention in TKR in patients with rheumatoid arthritis. Recently, Schai et $\mathrm{al}^{5}$ described a survival rate of $97 \%$ at 13 years in patients in whom the PCL had been retained at TKR. Using the Total Condylar Prosthesis and excising the PCL, Rogriguez et al $^{6}$ had good to excellent results in $81 \%$ of cases and a survival rate of the implant of $91 \%$ at 15 years. In our study, the survival rate of the implant remained at $90.7 \%$ from eight to 19 years. The clinical results were excellent in $75.8 \%$ of knees. The less striking improvement in function reflects both the advancing age of the patients over the period of follow-up and the effects of progressive systemic disease involving many joints.

In long-term studies, the number of patients often decreases because of death from natural causes. Higher rates of mortality have been reported in patients with rheumatoid arthritis than in those with osteoarthritis. ${ }^{21}$ At a follow-up of more than 13 years, over $60 \%$ of our patients had died. There was one death within three months of surgery.

The rate of infection of $1.5 \%$ in our study is similar to that shown previously ${ }^{1}$ and lower than that reported by others. ${ }^{6,15}$

The number of patients in our study is small, but it has uniformity and is complete; a single surgeon carried out all the TKRs, patients received uniform postoperative care, and none was lost to follow-up. The satisfactory clinical and radiological results support the use of PCL-retaining knee arthroplasty in rheumatoid arthritis.
No benefits in any form have been received or will be received from a commercial party related directly or indirectly to the subject of this article.

\section{References}

1. Gill GS, Joshi AB, Mills DM. Total condylar knee arthroplasty: 16- to 21-year results. Clin Orthop 1999;367:210-5.

2. Ewald FC, Wright RJ, Poss R, et al. Kinematic total knee arthroplasty: a 10- to 14-year prospective follow-up review. J Arthroplasty $1999 ; 14: 473-80$

3. Laskin RS, O'Flynn HM. Total knee replacement with posterior cruciate ligament retention in rheumatoid arthritis: problems and complications. Clin Orthop 1997;345:24-8.

4. Ritter MA, Herbst SA, Keating EM, Faris PM, Meding JB. Longterm survival analysis of a posterior cruciate-retaining total condylar total knee arthroplasty. Clin Orthop 1994;309:136-45.

5. Schai PA, Scott RD, Thornhill TS. Total knee arthroplasty with posterior cruciate retention in patients with rheumatoid arthritis. Clin Orthop 1999;367:96-106.

6. Rodriguez JA, Saddler S, Edelman S, Ranawat CS. Long-term results of total knee arthroplasty in class 3 and 4 rheumatoid arthritis. J Arthroplasty 1996;11:141-5.

7. Gill GS, Joshi AB. Long-term results of Kinematic Condylar Knee arthroplasty: analysis of 414 cases. J Bone Joint Surg [Br] 2001;83-B:355-8.

8. Gill GS, Mills DM. Long-term follow-up evaluation of 1000 consecutive cemented total knee arthroplasties. Clin Orthop 1991;273:66-76.

9. Insall JN, Dorr LD, Scott RD, Scott WN. Rationale of the Knee Society clinical rating system. Clin Orthop 1989;248:13-4.

10. Ewald FC. The Knee Society total knee arthroplasty roentgenographic evaluation and scoring system. Clin Orthop 1989;248:9-12.

11. Armitage P, Berry G. Statistical methods in medical research. Second ed. Oxford: Blackwell Scientific, 1987.

12. Wolfe F, Zwillich SH. The long-term outcomes of rheumatoid arthritis: a 23-year prospective, longitudinal study of total joint replacement and its predictors in 1600 patients with rheumatoid arthritis. Arthritis Rheum 1998;41:1072-82.

13. Robertsson O, Knutson $K$, Lewold S, Goodman S, Lidgren L. Knee arthroplasty in rheumatoid arthritis: a report from the Swedish Knee Arthroplasty Register on 4381 primary operations 1985 to 1995. Acta Orthop Scand 1997;68:545-53.

14. Kristensen O, Nafei A, Kjaersgaard-Andersen P, Hvid I, Jensen J. Long-term results of total condylar knee arthroplasty in rheumatoid arthritis. J Bone Joint Surg [Br] 1992;74-B:803-6.

15. Armstrong RA, Whiteside LA. Results of cementless total knee arthroplasty in an older rheumatoid arthritis population. J Arthroplasty 1991;6:357-62.

16. Carmichael E, Chaplin D. Total knee arthroplasty in juvenile rheumatoid arthritis: a seven-year follow-up study. Clin Orthop 1986;210:192-200.

17. Knutson K, Tjörnstrand B, Lidgren L. Survival of knee arthroplasties for rheumatoid arthritis. Acta Orthop Scand 1985;56:422-5.

18. Banks SA, Markovich GD, Hodge WA. In vivo kinematics of cruciate-retaining and -substituting knee arthroplasties. J Arthroplasty $1997 ; 12: 297-304$

19. Becker MW, Insall JN, Faris PM. Bilateral total knee arthroplasty: one cruciate retaining and one cruciate substituting. Clin Orthop 1991;271:122-4.

20. Ranawat CS. Results of cemented cruciate substituting and sacrificing total knee arthroplasty. Orthopedics 1996;19:787-8.

21. Bohm P, Holy T, Pietsch-Breitfeld B, Meisner C. Mortality after total knee arthroplasty in patients with osteoarthrosis and rheumatoid arthritis. Arch Orthop Trauma Surg 2000;120:75-8. 